\title{
PREPARATION AND PHOTOLUMINESCENCE PROPERTIES OF RF-SPUTTERED ZnO FILMS
}

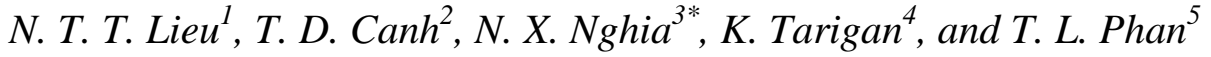 \\ ${ }^{1}$ Posts and Telecommunications Institute of Technology, Vietnam Posts and Telecommunications Group, Km 10, \\ Nguyen Trai, Hanoi, VIETNAM \\ ${ }^{2}$ Department of Physics, Hanoi University of Natural Science, 334 Nguyen Trai, Hanoi, VIETNAM \\ ${ }^{3}$ Institute of Materials Science, Academy of Science and Technology, 18 Hoang Quoc Viet, Hanoi, VIETNAM \\ ${ }^{4}$ Department of Mechanical Engineering, Mercu Buana University, Jakarta, INDONESIA \\ ${ }^{5}$ Department of Physics, Hankuk University of Foreign Studies, Yongin 449-791, SOUTH KOREA
}

\begin{abstract}
$\mathrm{ZnO} / \mathrm{Si}$ films were prepared by radio frequency (RF) magnetron sputtering at room temperature. By optimizing the heat treatment conditions, we obtained a good quality film annealed at $700{ }^{\circ} \mathrm{C}$ for longer 60 minutes. This process was monitored carefully by Raman scattering spectroscopy, and X-ray diffraction. The photoluminescence study on this film revealed that only ultraviolet emissions due to donor-acceptor pair (DAP), neutral acceptor-bound exciton $\left(\mathrm{A}^{\circ} \mathrm{X}\right)$ and donor-bound exciton $\left(\mathrm{D}^{\circ} \mathrm{X}\right)$ were observed. The intensity and peak position of these emissions depend on the measurement temperature and excitation power density.
\end{abstract}

Keywords: $\mathrm{ZnO}$ thin films, Preparation, Optical properties

*Corresponding author: Tel. (84 4) 37564693 Fax. (84 4) 38360705

E-mail address: nghianx@ims.vast.ac.vn

\section{Introduction}

$\mathrm{ZnO}$ is a transparently wide-band-gap semiconductor compound $\left(\mathrm{E}_{\mathrm{g}}=3.37 \mathrm{eV}\right)$ with the direct electronic transition, and has a large exciton binding energy of $60 \mathrm{meV}$ that ensures high luminescence efficiency at room temperature. It is considered as one of the most promising candidates for development of low-voltage and ultraviolet optoelectronic devices, transparent ultra-violet protection films, gas sensors, and so forth [1,2]. Recently, $\mathrm{ZnO}$ has attracted intensive interest because of new successes in synthesizing $\mathrm{ZnO}$ nanostructures that show many physically interesting properties, which are significant for applications in nanotechnology [3].

It is known well that photoluminescence (PL) behaviors of $\mathrm{ZnO}$ are sensitive to the preparation method and conditions [4-9]. Earlier reports revealed room-temperature PL spectra of $\mathrm{ZnO}$ usually consisting of an ultraviolet (UV) emission coming from bound excitons and/or a visible emission caused by defects, dopant, morphology, and/or excitation energy [6-11]. For high-quality $\mathrm{ZnO}$ samples, the ultra-violet (UV) emission is dominant in the whole spectrum range, and the free-exciton emission is observable at low temperatures and excitation energies [4,6,11].

Concerning preparation of $\mathrm{ZnO}$ films, there are some conventional methods such as molecular beam epitaxy (MBE), chemical vapor deposition (CVD), pulsed laser deposition (PLD), sol-gel, spray pyrolysis, and radio frequency (RF) magnetron sputtering that have been employed popularly [5-11]. Accordingly, the quality of films obtained depends strongly on many experimental factors, and heat treatment conditions. This is also the main reason to explain why experimental results reported by author groups are inconsistent. Recently, Kim et al. prepared $\mathrm{ZnO}$ films at room temperature using RFmagnetron sputtering. By varying RF power they obtained high-quality $\mathrm{ZnO}$ films with c-axis orientation [12].

In the present work, $\mathrm{ZnO}$ films were also grown on $\mathrm{Si}(100)$ substrates by RF-magnetron sputtering at room temperature. We based on the heat treatment to find out optimal conditions. This process was monitored carefully by Raman scattering spectroscopy and $x$-ray diffraction. Photoluminescence (PL) spectroscopy was used to investigate near-band-edge emissions of the film after obtained the optimal conditions.

\section{Experimental Detail}

$\mathrm{ZnO}$ films were grown on $\mathrm{Si}(100)$ substrates by RF-magnetron sputtering in an ambient Ar gas. The $\mathrm{ZnO}(4 \mathrm{~N})$ target was firstly sputtered without the 
substrates for 15 minutes to clean its surface, and then deposited on unheated $\mathrm{Si}$ substrates for 60 minutes. In order to stabilize the plasma source during the growing, the output power and working pressure were held at $150 \mathrm{~W}$ and 8.8 mTorr, respectively. The low-temperature prepared films were afterwards annealed in air (in a clean room) at temperatures $200-800{ }^{\circ} \mathrm{C}$ for $15-180$ minutes. Raman spectroscopy (LABRAM-1B, Jobin-Yvon) and $\mathrm{x}$-ray diffraction (X'Pert Phillips diffractormeter) were employed to monitor the quality of the films. Their morphology and thickness were characterized by scanning electron microscopy (SEM) using a Hitachi-600 and atomic force microscopy (AFM) using a Digital Instruments Nanoscope-3. For low-temperature PL measurements, the $\mathrm{ZnO}$ films were mounted on a cold finger of a closed-cycle helium cryostat (APD Cryonics Inc.) using copper paste. The measurement temperature was controlled by a Lakeshore-330 unit. A wavelength of $337.1 \mathrm{~nm}$ generated from a lowpressure nitrogen-gas laser (with a $10 \mathrm{~Hz}$ repetition rate and a 7-nm pulse width) was used as an excitation source. The excitation energy could be tuned by an optical filters system.

\section{Results and Discussion}

Fig. 1 shows representative Raman scattering (RS) spectra for $\mathrm{ZnO}$ films annealed at temperatures ranging from 200 to $500{ }^{\circ} \mathrm{C}$ for 60 minutes [Fig. 1(a)], and those annealed at $500{ }^{\circ} \mathrm{C}$ for $15-180$ minutes [Fig. 1(b)].

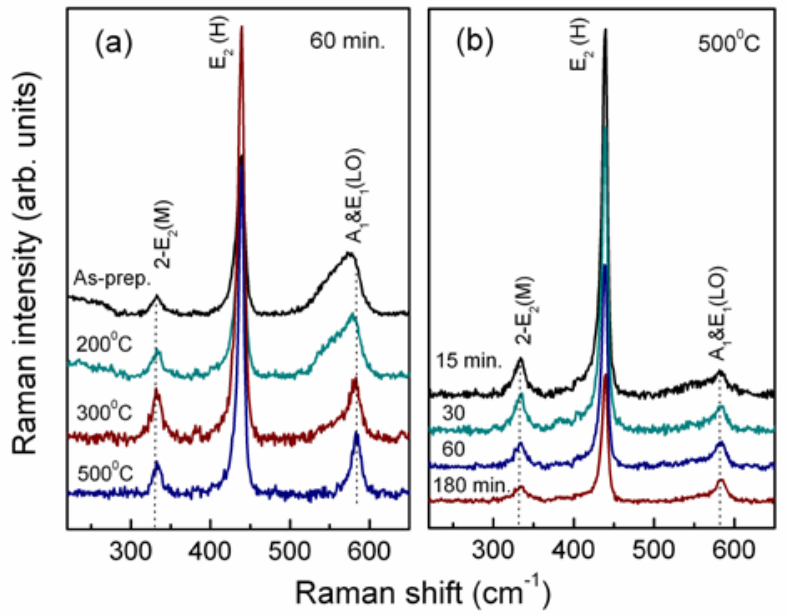

Fig. 1. The RS spectra for ZnO films annealed at (a) temperatures $200-500{ }^{\circ} \mathrm{C}$ for 60 minutes and (b) those annealed at $500{ }^{\circ} \mathrm{C}$ for 15 - 180 minutes.

It is similar to RS spectra of $\mathrm{ZnO}$ materials, conventional vibration modes $2-E_{2}(M), E_{2}(H)$ and $A_{1} \& E_{1}(\mathrm{LO})$ centered at 331,437 and 575 $\mathrm{cm}^{-1}$, respectively, are observed [13-15]. When the annealing temperature and time increase, the spectral lines become narrower and shift towards higher frequencies, revealing the change in microstructure of the films. This is more visible as considering the variation of a cusp around $564 \mathrm{~cm}^{-1}$, which is superimposed by two peaks. The first one is $A_{1} \& E_{1}(\mathrm{LO})$ centered at $575 \mathrm{~cm}^{-1}$ characterizing the crystalline phase and the other centered at 560 $\mathrm{cm}^{-1}$ characterizing the amorphous phase, see Fig. 1 [2,13-15]. Their relative Raman intensity changes strongly under the heat treatment conditions. Since the RS intensity is proportional to the scattering efficiency and a material amount contributed to the Raman scattering process, the crystalline volume fraction can be quantified from integrated intensities of the amorphous and crystalline peaks, $I_{\mathrm{a}}$ and $I_{\mathrm{c}}$, respectively [16].

$\chi_{C}=\frac{I_{c}}{I_{a}+\rho I_{c}}$

where $\rho$ is the ratio of the Raman efficiencies for crystalline and amorphous $\mathrm{ZnO}$. Assuming that $\mathrm{ZnO}$ crystals have a spherical shape with the crystalline size $d, \rho$ is given by

$$
\rho=0.1+e^{-d / 250}
$$

With $d>3 \mathrm{~nm}$, the dependences of the crystalline volume fraction on the annealing temperature and time obtained are shown in Fig. 2(a,b). We can see that for the films annealed at temperatures $200-500{ }^{\circ} \mathrm{C}$ the crystalline volume fraction increases when the annealing temperature increases, see Fig. 2(a). Meanwhile, at a given annealing temperature of $500{ }^{\circ} \mathrm{C}$ this fraction reaches above $85 \%$ as the annealing time is about $30-60$ minutes. It becomes unchanged with longer annealing times, see Fig 2(b). 


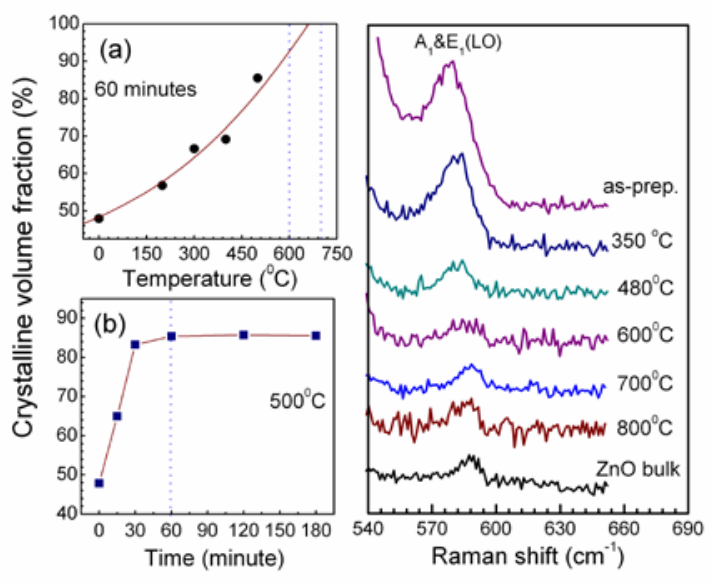

Fig. 2. The dependences of the crystalline volume fraction on (a) the annealing temperature and (b) time; (c) the RS spectra in the frequency range of $550-650 \mathrm{~cm}^{-1}$ for the annealed films compared with the RS spectrum of a $\mathrm{ZnO}$ single crystal..

To achieve a larger crystalline volume fraction, the as-prepared films need to be annealed at higher temperatures. By extrapolating to the $100 \%$ value, as graphed in Fig. 2(a), the annealing temperature is deduced to be about 600-700 ${ }^{\circ} \mathrm{C}$. In an attempt to verify the extrapolated temperature range, we annealed the films at higher temperatures up to $800{ }^{\circ} \mathrm{C}$ for 60 minutes. Fig. 2(c) shows the RS spectra in the frequency range of $550-650 \mathrm{~cm}^{-1}$ for these films compared with the RS spectrum of a $\mathrm{ZnO}$ single crystal. Clearly, for the film annealed at $700{ }^{\circ} \mathrm{C}$ the feature of the $A_{1} / E_{1}(\mathrm{LO})$ mode is similar to that of the crystalline bulk. When the film is annealed at $800{ }^{\circ} \mathrm{C}$, however, this peak shifts slightly towards a lower frequency, revealing the change in its structure.

To further understand the structural change taking place in the films as annealed at different temperatures for 60 minutes, x-ray diffraction was employed. As graphed in Fig. 3, the x-ray diffraction (XRD) patterns of the films annealed at temperatures below $600{ }^{\circ} \mathrm{C}$ appear a sharp peak centered at a diffraction angle of $34.4^{\circ}$ characterizing the crystalline phase.

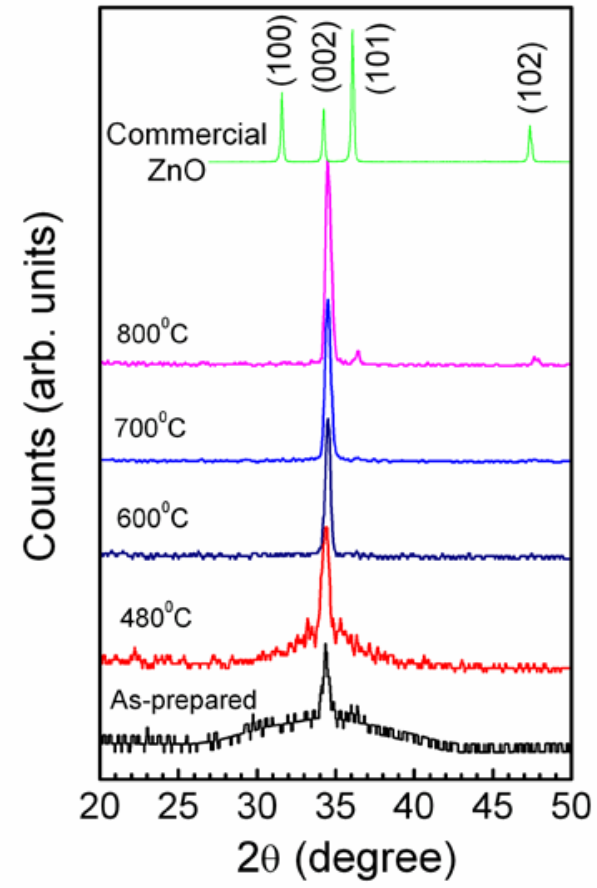

Fig. 3. The representative XRD patterns for the films annealed at temperatures $480-800^{\circ} \mathrm{C}$ for 60 minutes.

Its background is a broad peak, characteristic of the amorphous phase. However, at the annealing temperatures $600-700{ }^{\circ} \mathrm{C}$ only the peak coming from the crystalline structure is dominant, indicating the reduction of the amorphous phase [12]. If increasing the annealing temperature up to $800{ }^{\circ} \mathrm{C}$, the $\mathrm{XRD}$ pattern appears two additional peaks, see Fig. 3, i.e. the film has a polycrystalline structure. These observations are in good agreement with the RS data as mentioned above. Herein, by optimizing the heat treatment conditions we also obtained highquality $\mathrm{ZnO}$ films.

Physical processes happened to the films can be explained briefly as follows: during the film deposition by RF-magnetron sputtering in the ambient Ar gas, $\mathrm{Zn}$ and $\mathrm{O}$ atoms escaped from the $\mathrm{ZnO}$ target surface could react with each other to form stoichiometric $\mathrm{ZnO}$ crystals. However, there were also many other $\mathrm{Zn}$ atoms reacted with $\mathrm{O}$ atoms to form $\mathrm{ZnO}_{\delta}(\delta<<1)$ with an amorphous structure. Both these phases deposited randomly onto the $\mathrm{Si}$ substrates without rearranging in order or further reaction, since the substrates were not heated. This accounted for the appearance of the sharp XRD peak at $34.4^{\circ}$ backgrounded by the broaden line for the as-prepared films, see Fig. 3. 
Furthermore, the RS spectra in this case emerged the cusp around $564 \mathrm{~cm}^{-1}$ overlapped by the two modes as mentioned above. When the films were annealed at different temperatures, the $\mathrm{ZnO}$ crystals would rearrange in order, and $\mathrm{ZnO}_{\delta}$ reacted with oxygen in air to become stoichiometric $\mathrm{ZnO}$ crystals (i.e. $\delta \rightarrow$ 1 ). Thus, the crystalline volume fraction of the films increased with increasing the annealing temperature $\left(T_{\mathrm{an}}\right)$ and time $\left(t_{\mathrm{an}}\right)$, regarding the increase in the (002)-XRD peak intensity and the narrowing of the cusp around $564 \mathrm{~cm}^{-1}$ in the RS spectra. At the optimal condition $\left(T_{\text {an }}=700\right.$ ${ }^{\circ} \mathrm{C}$ and $t_{\mathrm{an}} \geq 60$ minutes), $\mathrm{ZnO}_{\delta}$ transformed completely to the stoichiometric formation (i.e. $\delta=1$ ), and the $\mathrm{ZnO}$ crystals with a good orientation were observed. Accordingly, the XRD pattern appeared only a sharp peak, and the RS-peaks intensity increased, no RS mode from the amorphous phase was observed.

Fig. 4 shows SEM and AFM images for the film annealed at $700{ }^{\circ} \mathrm{C}$ for 60 minutes.

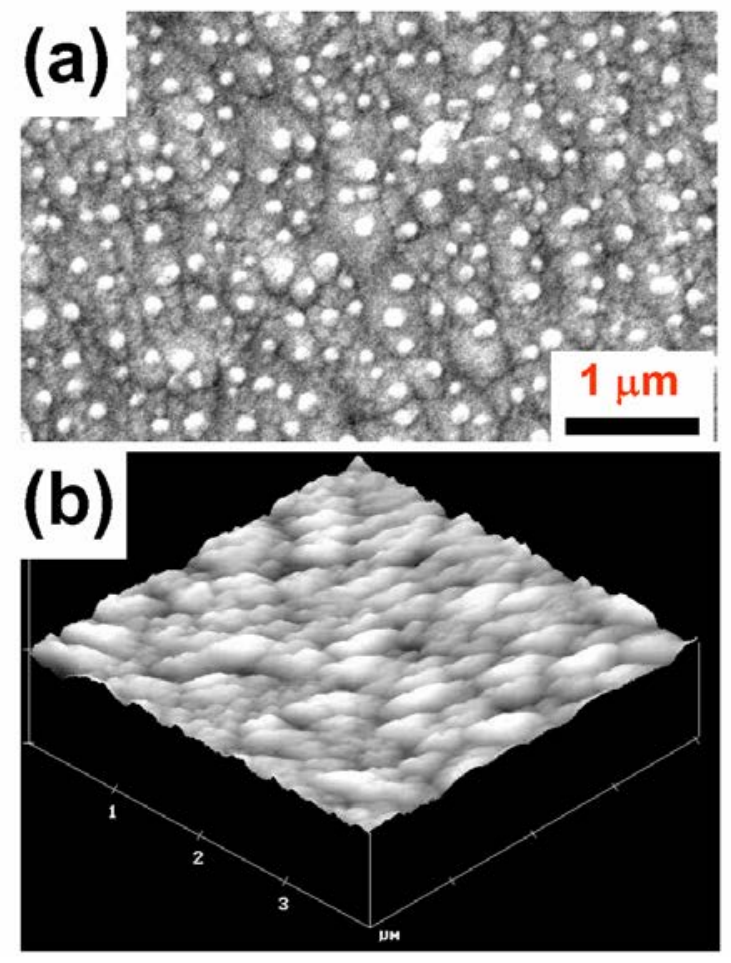

Fig. 4. SEM and AFM images show the morphology for the film annealed at $700{ }^{\circ} \mathrm{C}$ for 60 minutes.

As a result, its morphology is uniform. The thickness and surface roughness of the film were determined to be about $1.5 \mu \mathrm{m}$ and $20 \mathrm{~nm}$, respectively. These characteristics make sure that PL spectra recorded on different sample areas are similar.

As an additional evidence that further confirmed the quality of the $\mathrm{ZnO}$ film annealed at $700{ }^{\circ} \mathrm{C}$ for 60 minutes, Fig. 5 shows roomtemperature PL spectra for the as-prepared, $T_{\text {an }}$ $=700$ and $800{ }^{\circ} \mathrm{C}$ films. There is no PL signal to from the as-prepared film, meaning that the amorphous phase is not favorable for PL emission. However, the PL signal is improved rapidly as increasing $T_{\mathrm{an}}$. For the film annealed at $700{ }^{\circ} \mathrm{C}$, only two peak emissions in the ultraviolet (uv) region are dominant over the whole spectrum range studied, showing that the film has a good quality [6,7]. If increasing $T_{\text {an }}$ above $700{ }^{\circ} \mathrm{C}$, for example $T_{\text {an }}=800{ }^{\circ} \mathrm{C}$ as graphed in Fig. 5, besides the uv emissions there is the appearance of a visible emission centered at $2.4 \mathrm{eV}$. The origin of this emission is still a controversial matter, which needs to be further studied [17,18]. In our work, we only concentrate on investigating PL spectra of the good-quality film with $T_{\mathrm{an}}=700{ }^{\circ} \mathrm{C}$ and $t_{\mathrm{an}}=60$ minutes.

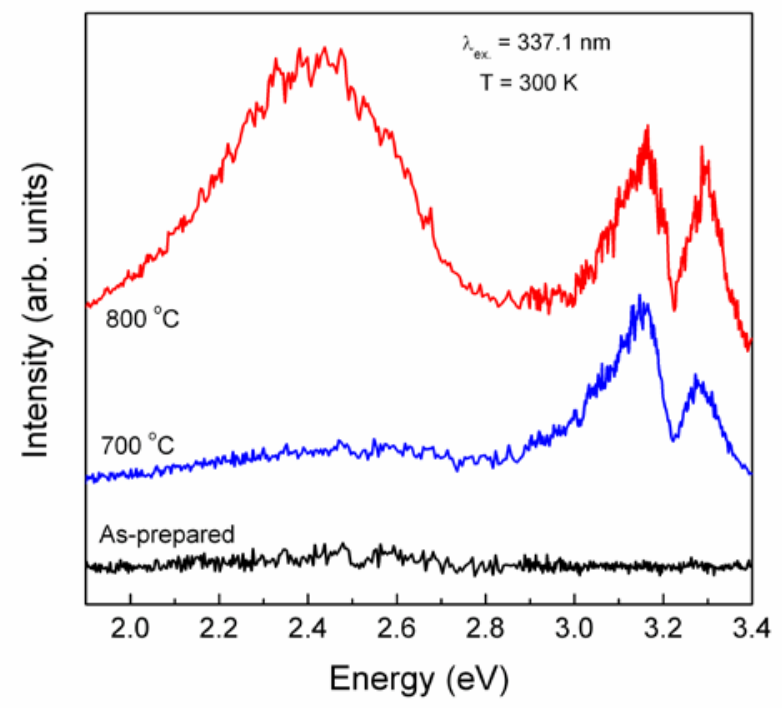

Fig. 5. The room-temperature PL spectra for the films annealed at 700 and $800{ }^{\circ} \mathrm{C}$ for 60 minutes compared to the PL spectrum of the as-prepared one.

In an attempt to clarify the origin of the uv emissions, we have studied dependence of the emissions on the measurement temperature and excitation power density for the $T_{\text {an }}=700{ }^{\circ} \mathrm{C}$ sample. Fig. 6 (a) shows the PL spectra of the 
film at some measurement temperatures with an excitation power density of $13 \mathrm{~kW} / \mathrm{cm}^{2}$.

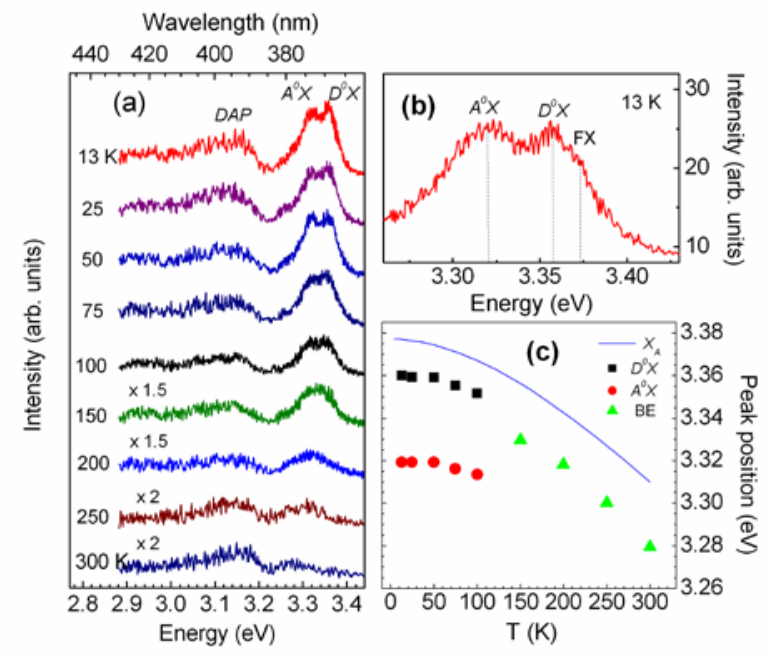

Fig. 6: (a) The PL spectra of the $T_{a n}=700{ }^{\circ} \mathrm{C}$ film at different measurement temperatures under an excitation power density of $13 \mathrm{~kW} / \mathrm{cm}^{2}$; (b) the emission peaks of $A^{\circ} X, D^{\circ} X$ and $F X$; (c) the temperature dependence of the $A^{\circ} X$ - and $D^{\circ} X$-peak emissions compared with that of the $F X$ emission in a $\mathrm{ZnO}$ bulk crystal, solid line $\left(X_{A}\right)$.

It is different from the room-temperature spectrum, the PL spectra recorded at low temperatures below $100 \mathrm{~K}$ appear three peaks centered at 3.137, 3.317 and $3.360 \mathrm{eV}$ (determined at $13 \mathrm{~K}$ ). Among them, the 3.137 $\mathrm{eV}$ peak is attributed to the donor-acceptor pair (DAP) transition, its physical nature is presented afterwards [19]. Besides these emissions, a shoulder at the high-energy side centered at $3.373 \mathrm{eV}$ is also observed, which is associated with the free-exciton (FX) transition, see Fig. 6(b) $[6,7]$. According to earlier reports, the distance between FX and neutral donor-bound exciton $\left(\mathrm{D}^{\circ} \mathrm{X}\right)$ emissions obtained is about 12 $15 \mathrm{meV}[6,7,10,18]$. This suggests that the 3.360 $\mathrm{eV}$ peak in our case belongs to $\mathrm{D}^{\circ} \mathrm{X}$. For the $3.137 \mathrm{eV}$ peak, its origin is not specified $[10,19$ $22]$. We believe that it comes from the acceptorbound exciton $\left(\mathrm{A}^{\circ} \mathrm{X}\right)[10,19,22]$ rather than from the DAP one [20,21]. This assertion is based on studying the excitation-power-density dependence of the DAP and $\mathrm{A}^{\circ} \mathrm{X}$ emissions.

As shown in Fig. 6(a), with increasing temperature from $13 \mathrm{~K}$ the intensity of the $\mathrm{D}^{\circ} \mathrm{X}$ and $\mathrm{A}^{\circ} \mathrm{X}$ emissions decreases gradually while their peak position shifts towards lower energies, which has a similar tendency for the temperature dependence of the free-exciton
(FX) emission $\left(\mathrm{X}_{\mathrm{A}}\right)$ in the $\mathrm{ZnO}$ bulk crystal, see Fig. 6(c) [5]. At temperatures above $100 \mathrm{~K}$, however, besides the persisting existence of the DAP emission the $\mathrm{D}^{\circ} \mathrm{X}$ and $\mathrm{A}^{\circ} \mathrm{X}$ peaks are overlapped each other. Their sum peak also shifts towards lower energies, denoted as BE in Fig. 6(c).

To further understand the intrinsic of DAP, $\mathrm{D}^{\circ} \mathrm{X}$, and $\mathrm{A}^{\circ} \mathrm{X}$ emissions, we have studied the PL spectra of the film at $13 \mathrm{~K}$ when the excitation power density varied from 5 to about $10^{6} \mathrm{~kW} / \mathrm{cm}^{2}$. The PL spectra recorded are shown in Fig. 7.

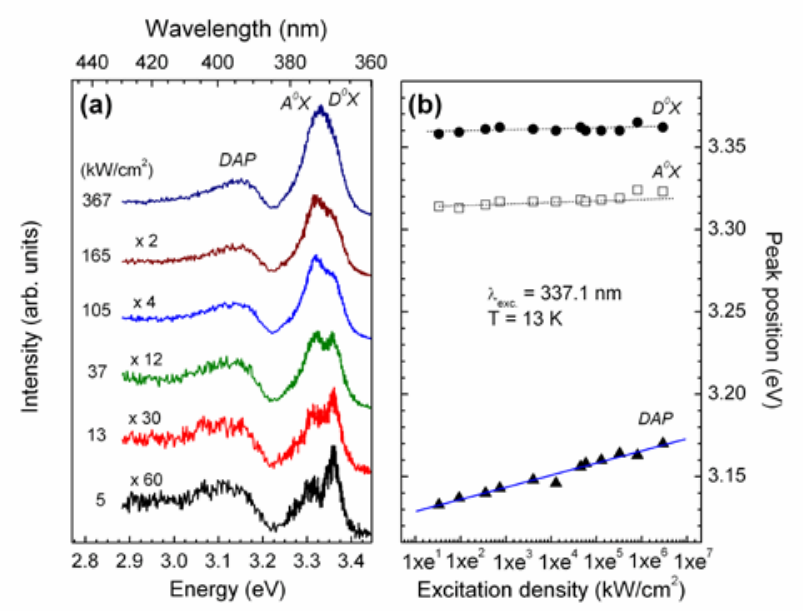

Fig. 7 (a) The PL spectra of the $T_{a n}=700{ }^{\circ} \mathrm{C}$ film measured at $13 \mathrm{~K}$ with the excitation power density varying from 5 to about $10^{6} \mathrm{~kW} / \mathrm{cm}^{2}$; (b) the variation of the $D A P, D^{\circ} X$, and $A^{\circ} X$ peaks with the excitation power density, the dotted lines for $D^{\circ} X$ and $A^{\circ} X$ guide the eye only, and the solid line for DAP is the fitting curve to Eq. (3).

At low excitation power densities of below 367 $\mathrm{kW} / \mathrm{cm}^{2}$, we can see the clear separation of $\mathrm{D}^{\circ} \mathrm{X}$ and $\mathrm{A}^{\circ} \mathrm{X}$ emissions. With increasing the excitation density from $5 \mathrm{~kW} / \mathrm{cm}^{2}$, the intensity of all the emissions (DAP, $\mathrm{D}^{\circ} \mathrm{X}$, and $\mathrm{A}^{\circ} \mathrm{X}$ ) increases. However, the $\mathrm{A}^{\circ} \mathrm{X}$-emission intensity becomes stronger and dominant as the excitation power density is above $37 \mathrm{~kW} / \mathrm{cm}^{2}$. This reveals that the acceptor concentration in the $T_{\text {an }}=700$ ${ }^{\circ} \mathrm{C}$ film is quite large, probably since nitrogen in air diffused in the $\mathrm{ZnO}$ host lattice during the heat treatment $[6,19,23]$. At excitation power densities above $367 \mathrm{~kW} / \mathrm{cm}^{2}$ the $\mathrm{D}^{\circ} \mathrm{X}$ and $\mathrm{A}^{\circ} \mathrm{X}$ emissions become overlapped. This situation is similar to the case of the high-temperature PL spectra, see Fig. 6(a). Having analyzed variation of the emissions versus the excitation density, 
the following features are observed: (i) the $\mathrm{D}^{\circ} \mathrm{X}$ and $\mathrm{A}^{\circ} \mathrm{X}$ peaks seem unchanged in their position; this result is in good agreement with identifying $\mathrm{A}^{\circ} \mathrm{X}$ as discussed above. (ii) The DAP peak shifts to higher energies, which could be described by an exponential function $[19,22]$

$I_{\mathrm{exc}} \propto \exp \left(\omega_{\mathrm{p}} / \beta\right)$

where $I_{\text {exc }}$ and $\omega_{p}$ are the excitation density and the peak position, respectively, and $\beta$ is a parameter dependence of the compensation ratio ( $\beta=4.2 \mathrm{meV}$, in our case), see Fig. 7(b). The high-energy shift of the DAP peak $\left(E_{\mathrm{DAP}}\right)$ can be explained by means of an expression [24]

$$
E_{D A P}=E_{g}-\left(E_{D}+E_{A}\right)+\frac{e^{2}}{4 \pi \varepsilon r}
$$

where $E_{\mathrm{D}}$ and $E_{\mathrm{A}}$ are the binding energies of donor and acceptor states, respectively. And, e, $\varepsilon$, and $r$ are the electric charge, dielectric constant, and the distance of the donor-acceptor pair, respectively. At low temperatures, the distance of the donor-acceptor pair decreases when the excitation power density increases, resulting in the high-energies shift of the DAP peak. It is used this feature to identify the DAP emission in $\mathrm{ZnO}$.

\section{Conclusions}

A good quality $\mathrm{ZnO}$ thin film was grown by RF-magnetron sputtering. Influence of temperature and excitation power density on the near-band-edge emissions of the sample was studied. At low temperatures and excitation power densities, the emissions coming from DAP, $\mathrm{A}^{\circ} \mathrm{X}$ and $\mathrm{D}^{\circ} \mathrm{X}$ centered at 3.137, 3.317 and $3.360 \mathrm{eV}$, respectively, were observed. However, at temperatures above $100 \mathrm{~K}$ and/or high excitation densities the $\mathrm{A}^{\circ} \mathrm{X}$ and $\mathrm{D}^{\circ} \mathrm{X}$ emissions became overlapped. The change in their peaks position with respect to temperature and the excitation power density was analyzed and discussed.

\section{Acknowledgements}

This work is supported by National Foundation for Science and Technology Development of Vietnam (Grant No 103.06-2012.43).

\section{References}

[1] Pearton, S. J. Norton, D. P. lp, K. Heo, Y. W. \& Steiner, T. J. Vac. Sci. Technol. 2004; B 22, 932.

[2] U. Ozgur, Alivov, Ya. I. Liu, C. Teke, A. Reshchikov, M. A. Dogan, S. Avrutin, V. Cho, S.-J. \& Morkoc, M. Appl. Phys. 2005; Rev. 98, 041301.

[3] Wang, Z. L. J. Phys.: Condens. Matter 2004; 16, R829.

[4] Lieu, N. T. T. Dat, D. H. \& Liem, N. Q. Acta Phys. Pol. 2003; A 103, 67.

[5] Leung, Y. H. Kwok, W. M. Djurisic, A. B. Phillips, D. L. \& Chan, W. K. Nanotechnology 2005; 16, 579.

[6] Fujita, T. Chen, J. \& Kawaguchi, D. Jpn. J. Appl. Phys. 2003; 42, L834.

[7] Wang, D. Liu, Y. C. Mu, R. Zhang, J. Y. Lu, Y. M. Shen, D. Z. \& Fan, X. W. J. Phys.: Condens. Matter 2005; 16, 4635.

[8] A. B. Djurisic, Y. H. Leung, K. H. Tam, L. Ding, W. K. Ge, H. Y. Chen, \& Gwo, S. Appl. Phys. Lett. 2006; 88, 103107.

[9] Shi, W. S. Cheng, B. Zhang, L. \& Samulski, E. T. J. Appl. Phys. 2005; 98, 083502.

[10] Chen, J. \& Fujita, T. Jpn. J. Appl. Phys. 2002; 41, L203.

[11] Shan, W. Walukiewicz, W. Ager III, J. W. Yu, K. M. Yuan, H. B. Xin, H. P. Cantwell, G. \& Song, J. J. Appl. Phys. Lett. 2005; 86, 191911.

[12] Kim N. H. \& Kim, H. W. British Ceramic Transactions 2004; 103, 15.

[13] Ozgur, U. Alivov, Y. I. Liu, C. Teke, A. Reshchikov, M. A. Dogan, S. Avrutin, V. Cho, A.-J. \& Morkoc, H. J. Appl. Phys. 2005; 98, 041301.

[14] Ashkenov, N. Mbenkum, B. N. Bundesmann, C. Riede, V. Lorenz, M. Spemann, D. Kaidashev, E. M. Kasic, A. Schubert, M. Grundmann, M. Wagner, G. Neumann, H. Darakchieva, V. Arwin, H. \& Monemar, B. J. Appl. Phys. 2003; 93, 126.

[15] Ye, J. D. Gu, S. L. Zhu, S. M. Liu, S. M. Zheng, Y. D. Zhang, R. Shi, Y. 
Chen, Q. Yu, H. Q. \& Ye, Y. D. Appl.

Phys. Lett. 2006; 88, 101905.

[16] Viera, G. Huet, S. \& Boufendi, L. J. Appl. Phys. 90, 4175 (2001).

[17] Teng, X. M. Fan, H. T. Pan, S. S. Ye, C. \& Li, G. H. J. Appl. Phys. 2006; 100, 053507.

[18] Tamura, K. Makino, T. Tsukazaki, A. Sumiya, M. Fuke, S. Furumochi, T. Lippmaa, M. Chia, C. H. Segawa, Y. Koinuma H., \& Kawasaki, M. Solid State. Comm. 2003; 127, 265.

[19] Meyer, B. K. Alves, H. Hofmann, D. M. Kriegseis, W. Forster, D. Bertram, F. Christen, J. Hoffmann, A. Straßburg, M. Dworzak, M. Haboeck, U. \& Rodina, A. V. Phys. Stat. Sol. 2004; (b) 241, 231.

[20] Matsumoto, T. Kato, H. Miysmoto, K. Sano, M. EZhukov, . A. \& Yao, T. Appl. Phys. Lett. 2002; 81, 1231.

[21] Nakahara, K. Takasu, H. Fons, P. Yamada, A. Iwata, K. Matsubara, K. Hunger, R. \& Niki, S. Appl. Phys. Lett. 2001; 79, 4139.

[22] Xiu, F. X. Yang, Z. Mandalapu, L. J. \& Liu, J. L. Mater. Res. Soc. Symp. Proc. 892, 0892-FF18-09-EE09-09.1 (2006).

[23] Guo, B. Qiu, Z. R. \& Wong, K. S. Appl. Phys. Lett. 2003; 82, 2290.

[24] Yu, P. Y. \& Cardona, M. Fundamentals of Semiconductor: Physics and Materials Properties, Berlin Heidelberg: Springer-Verlag; 1996. 